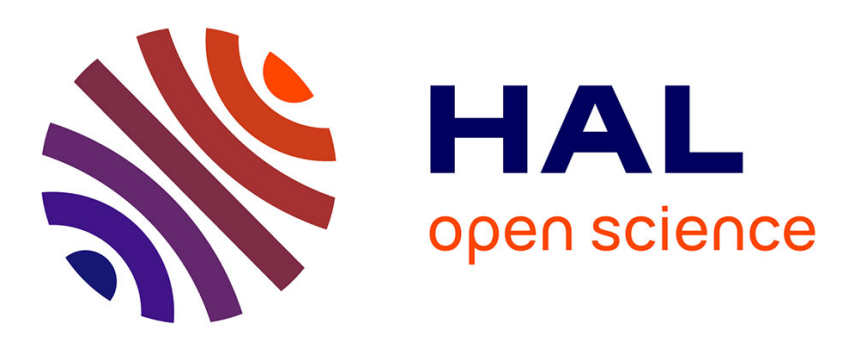

\title{
Market inconsistencies of the market-consistent European life insurance economic valuations: pitfalls and practical solutions
}

Nicole El Karoui, Stéphane Loisel, Jean-Luc Prigent, Julien Vedani

\section{- To cite this version:}

Nicole El Karoui, Stéphane Loisel, Jean-Luc Prigent, Julien Vedani. Market inconsistencies of the market-consistent European life insurance economic valuations: pitfalls and practical solutions. European Actuarial Journal, 2017, 7 (1). hal-01242023

\section{HAL Id: hal-01242023 \\ https://hal.science/hal-01242023}

Submitted on 11 Dec 2015

HAL is a multi-disciplinary open access archive for the deposit and dissemination of scientific research documents, whether they are published or not. The documents may come from teaching and research institutions in France or abroad, or from public or private research centers.
L'archive ouverte pluridisciplinaire $\mathbf{H A L}$, est destinée au dépôt et à la diffusion de documents scientifiques de niveau recherche, publiés ou non, émanant des établissements d'enseignement et de recherche français ou étrangers, des laboratoires publics ou privés. 


\title{
Market inconsistencies of the market-consistent European life insurance economic valuations: pitfalls and practical solutions
}

\author{
Nicole EL KAROUI* \\ Stéphane LOISEL ${ }^{\dagger}$ \\ Jean-Luc PRIGENT \\ Julien VEDANI ${ }^{\S}$
}

Dec. 11th, 2015

\begin{abstract}
The Solvency II directive has introduced a specific so-called risk-neutral framework to valuate economic accounting quantities throughout European life insurance companies. The adaptation of this theoretical notion for regulatory purposes requires the addition of a specific criterion, namely the market-consistency, in order to objectify the choice of the valuation probability measure.

This paper aims at pointing out and fixing some of the major risk sources embedded in the current regulatory life insurance valuation scheme. We compare actuarial and financial valuation schemes. We then address first operational issues and potential market manipulation sources in life insurance, induced by both theoretical and regulatory pitfalls. For example, we show that calibrating the interest rate model in October 2014 instead of December $31^{\text {st }} 2014$ generates a 140\%-increase in the economic own funds of a representative French life insurance company. We propose various adaptations of the current implementations, including product-specific valuation scheme, to limit the impact of these market-inconsistencies.
\end{abstract}

Key words risk-neutral valuation, economic valuation, market-consistency, European regulation, life insurance.

\footnotetext{
*Université Pierre et Marie Curie - Paris 6, Laboratoire de Probabilité et Modèles Aléatoires, and Ecole Polytechnique, Centre de Mathématiques APpliquées, Paris, France, Email: nicole.el_karoui@upmc.fr

†Université de Lyon, Université Claude Bernard Lyon 1, Laboratoire de Science Actuarielle et Financière, Institut de Science Financière et d'Assurances, Lyon, France, Email: stephane.loisel@univ-lyon1.fr

†Université de Cergy-Pontoise, Laboratoire de Théorie Économique, Modélisation et Applications, Cergy-Pontoise, France, Email: jean-luc.prigent@u-cergy.fr

§Université de Lyon, Université Claude Bernard Lyon 1, Laboratoire de Science Actuarielle et Financière, Institut de Science Financière et d'Assurances, Lyon, France, Email: julien.vedani@etu.univ-lyon1.fr
} 


\section{Introduction}

Since the mid-2000s, the life insurance industry tends massively to consider prospective Monte Carlo type pricing approaches to evaluate their liability portfolios. In particular, the various hidden options, the great granularity of the policyholders, and the numerous underlying risks (see e.g. Toseti, Paris, Paslky \& Le Vallois (2003)) have led European practitioners to consider such schemes for life insurance products valuation. This is indicative of the increasingly complex framework shaped by the successive Solvency I and Solvency II directives. The high complexity of these European directives aims at better understanding the risks and at better taking the products optionality into account. It was supposed to lead progressively to a safer market and greater European regulation.

In practice, these life insurance valuations are implemented based on so-called economic scenarios. These scenarios are simulations of the financial risks, throughout which the liabilities cash-flows of the valuated product are projected on a long time horizon. The actuarial practitioners can establish a best estimate, by Monte Carlo estimation, of their products liabilities portfolio. The general process is very similar to Monte Carlo financial assets' pricing methodologies (see e.g. Jäckel \& Bubley (2002) or Glasserman (2004)). The probability measure considered to simulate the valuation scenarios is currently denoted as risk-neutral by practitioners (see Devineau \& Loisel (2009), Vedani \& Devineau (2013)), with the underlying idea that the final values are obtained under a risk-neutral probability measure. This use of the financial (see Black \& Scholes (1973), Merton (1971) and the more recent book Bingham \& Kiesel (2004)) risk-neutral terminology reflects a will to bring the insurance regulation closer to the financial one, but is, in this specific life insurance liability valuation scheme, quite different from its original formulation.

The valuation framework used by the actuaries leads to different homogenization issues. The nonuniqueness of the valuation measure requires the introduction of an additional probability measure selection constraint, the market-consistency criterion. The practical valuation process is very pragmatic, supposedly easy to implement and regulate.

In addition to the practical presentation and comparison of both financial and actuarial risk-neutral valuation schemes, the main contribution of our paper is to point out and exemplify several major theoretical and regulatory pitfalls, introducing numerous subjective choices and manipulation opportunities. We also propose first alternatives to the regulatory valuation scheme such as new, product-specific and less manipulable calibration processes. These refinements directly aim at providing a safer and more comparable actuarial valuation framework.

In Section 1, we recall the historical goals of the risk-neutral probability measure theory and the way market finance practitioners deal with risk-neutral valuation, its daily use and theoretical requirements. In Section 2, we develop the European life insurance use of this notion through regulation requirements and present two cases of operational application. This leads us to introduce the market-consistency criterion, considering the definition generally accepted through the operational actuarial literature. This enables us to compare the financial and insurance valuation practices. In Section 3 we address specific operational issues leading to relative market-inconsistencies, easy market manipulations and a strong incomparability of final valuations. Through various exemplifications of these focal points, we underpin new, important research questions and propose first alternatives to the actual valuation scheme. 


\section{The risk-neutral probability measure in finance}

This section aims at introducing the initial framework that led to the concept of a risk-neutral probability measure and how it is used in practical finance. This short presentation is important for our paper as it enables us to replace the risk-neutral framework in its context in order to better understand the difficulties implied by its use in real market conditions, and finally in the current European actuarial valuation process.

\subsection{Historical bases}

The history of the risk neutral valuation financial scheme is fully embedded within the development of derivatives markets during the last half century.

At the end of World War II, the Bretton Woods agreements (1944) stress the first basements of a global monetary organization by spelling out the rules of an international monetary system and the means to put its principles into practice and maintain. Even if the famous British economist, Keynes, the world specialist of currency, was very engaged in this project, it is finally the American proposition which was retained. The agreements established the supremacy of the dollar, while maintaining its indexed on gold, contrary to the opinion of Keynes. It laid the foundations of an increasingly global system of production and finance; for a quarter century, the economic expansion was unprecedented.

At the same period, the academic world of economic research experienced a strong emulation around the general equilibrium theory introduced by Walras in 1874. In 1954, K.J. Arrow and G. Debreu in their work on general equilibrium theory under uncertainty, introduced the "Arrow-Debreu" prices as the prices of atomic time and state contingent claims which deliver one unit of a specific consumption good if a specific uncertain state realizes at a specific future date; these atomic prices allow agents to exchange state and time contingent claims on goods at the equilibrium. In financial economics, ArrowDebreu securities delivering one unit of the numéraire good can be viewed as natural atomic building blocks for all other state-time contingent financial claims; their prices determine a unique arbitrage-free "risk-neutral" price system (see Becherer \& Davis (2008)). This view is still deeply embedded in the anglo-saxon culture probably because of the importance that is given to it in business schools. The same idea was developed by L. Bachelier in 1900 in his PhD thesis, "Theorie de la speculation" from a more financial point of view.

However, the uneven growth of world economies, divergent monetary and fiscal policies, and international liquidity constraints caused the demise of the Bretton Woods system in 1971, when US removed the direct convertibility of the US dollar to gold. This date is one of the most significant turning points in the history of financial economy. It opened an era of financial globalization, encouraged by the deregulation not just of currency markets, interest rates but also through rules about banking and investment. The considerable risk induced by price fluctuation resulted in the creation of currency and interest rate financial instruments to hedge against those fluctuations. In 1973, the Chicago Board Options Exchanges (CBOE) is founded and becomes the first marketplace for trading listed options. Since then, new futures exchanges have been founded in different places (in Paris MATIF (1986)) and have developed innovative financial hedging instruments. All three prerequisites for a well-functioning market, namely safety, efficiency and innovation, are fulfilled. Derivatives are totally different from securities. They make future 
risks tradable by thinking first in terms of dynamic risk transfer, by using portfolios that have the same payoff as the derivative, with the same time-comovements. The price of the derivatives is settled as the value of the replicating (hedging) portfolio, following the no-arbitrage principle. New concepts were necessary to implement these ideas at large scale in a business perspective.

The idea to introduce dynamic portfolios in option theory is due to Black \& Scholes (1973) and Merton (1971), influenced by the modern portfolio theory, proposed by Markowitz (1952). Markowitz has formulated the portfolio problem as a choice of the mean and variance of a portfolio of assets, and has shown that diversification helps to reduce the risk. In the derivative market, where contracts grant future cash-flows on a tradable assets, Black, Scholes and Merton's solution is to use an inter-temporal day-to day diversification based on trading the underlying asset. Indeed, the products, once coupled to their "hedging" portfolios, become insensitive to the returns of the underlying and to the market trend. There only remains a fluctuation risk depending on the underlying and on the product considered, which in the Black-Scholes-Merton theory may be reduced to zero by the optimal hedging portfolio (if continuous trades are available). Prices and hedges are then computed simultaneously from a parsimonious model of the day-to-day fluctuation of the underlying and from an argument based on stochastic differential calculus (Black Scholes formula, and Delta hedge). As a by-product, the pricing rule is additive, and the Arrow-Debreu decomposition is still valid. It is based on the hedging price (also called "state price density" ) of contingent claims which deliver one unit of numéraire if a specific uncertain state realizes at a specific future date (atomic building block). The Arrow-Debreu prices were static, when derivatives are traded dynamically over time. As a consequence, these state price density processes may be time consistent with respect to the information revealed over the course of time, without bias. Therefore, they may be associated with a risk-neutral probability measure, whose state price density corresponds to likelihood. Finally, the price in a given numéraire is the conditional risk-neutral expectation of the terminal cash-flow given the available information. In practice, this rule is fully derived from the protection of products through hedging.

However the existence of a perfect hedging strategy is very theoretical since there are too many sources of risk to be hedged (this corresponds to market incompleteness). Fortunately, the original riskneutral theory can be extended to the incomplete market case, leading to theoretical no-arbitrage bid-ask spreads for option pricing (see Kreps (1981)). The upper price corresponds for example to the price of the superhedging strategy. Under mild assumptions, any no-arbitrage price corresponds to a risk-neutral valuation under one particular risk-neutral probability. Specific imperfect hedging strategies can be based on the minimization of the quadratic hedging risk or on the control of some given quantiles of the hedging error. Note also that rational bid-ask spreads can be determined in the presence of transaction costs or / and specific constraints on trading strategies (no short-selling for instance) but such theoretical and complex extensions often lack explicit pricing and hedging formulas.

\subsection{Use and management of risk-neutral valuation through financial markets}

Today, the ideas of Black-Scholes-Merton based on hedging requirement are still in use. Nowadays, for each derivative, traders must continuously update the corresponding hedging portfolio: it is a prerequisite for any trade. In practice, it is necessary to associate a product with its hedging portfolio to make it neutral with respect to its market risk, to its specific drift and volatility, in order to use risk-neutral valuation. 
Traders manage this task very regularly in order to make their hedging strategy efficient and their riskneutral valuations fair and legitimate.

The market imperfections nevertheless have two strong consequences on the financial business practices.

- First, the valuation probability measure is not unique for every product. Similarly to the fact one has to assess almost one hedging portfolio for each derivative, one obtains almost one valuation measure for each product.

- Second, the final price is not unique either. Market data providers only present a rebuilt information, based on the last trades of the day or on smoothing and interpolation/extrapolation methods when no trade has occurred.

In practice, the fluctuations of supply and demand lead to trading prices that move constantly but that tend, from one day to another, to adjust towards their fair value. The valuation measure used to valuate each product therefore changes each day to adapt to new underlying prices and buyers/sellers expectations.

As a conclusion the practical use of risk-neutral valuation is adapted and should be restricted to the derivatives market. In order to produce prices that are useful for practitioners, this requires both to hedge and to update every day all valuation measures, models, prices and positions (every trader's position is closed at the end of each day).

As far as the insurance economic valuation is concerned, the use of the risk-neutral valuation framework is questionable because the link between model and objective seems broken. Is it useful and legitimate though risk neutral valuation has clearly been designed for a different purpose? First of all, it seems difficult to adapt it to the deeply illiquid insurance market. In addition, technical risks are non-hedgeable and lead to a major disturbance when trying to legitimate the framework. One of the major practical difficulties is the multiplicity of potential valuation probability measures: how to select the risk-neutral measure for such atypical products? This issue is partly solved by the use of a constraint when choosing the valuation measure, market-consistency.

Today risk-neutral valuation is a basement of practical business, accounting (IFRS) and solvency regulation (Basel III) for market finance. This market valuation has a real meaning as far as financial products are concerned. In parallel and though the link is not evident for every kind of business, it progressively becomes a standard, not for day-to-day practice but for worldwide accounting regulation. In Section 2 we begin by recalling the historical development of this concept regarding insurance solvency regulation.

\section{The risk-neutral probability measure in life insurance}

After introducing the main points in the European regulation historical developments and current framework related to the use of risk-neutral probability measure, this section provides a wide development of operational actuarial practices using this valuation scheme. 


\subsection{The European regulatory framework}

This subsection is the opportunity to trace the historical roots of risk-neutral valuation as a key feature for European life insurance regulation.

\subsubsection{Historical developments}

When considering the recent evolutions of the European regulation and the introduction of risk-neutral valuation in actuarial practices, it is important to focus first on the new international accounting norms that developed in parallel. The International Financial Reporting Standards (IFRS) first introduce the notion of fair valuation for insurance liabilities, with, in particular, the IFRS 4 that directly concerns the fair valuation of insurance contracts.

The IFRS norms come from an accounting will highly geared toward stockholders. They introduce the need for fair accounting, instead of historical accounting, especially to reflect better the instantaneous reality of a balance sheet, more in line with the investors and stockholders interest.

The IFRS 2005 European regulation, published in the European Commission Official Journal on 09/11/02, renders the IFRS norms compulsory for listed European companies that publish consolidated financial statements, from 01/01/05 on. The European undertakings have to assess the fair value of their liabilities that can be seen as their trading value. This value is easy to interpret for financial assets that are regularly traded on their markets, but it is a counter-intuitive concept for a market which underlying is so illiquid.

Still gearing towards stockholders, the life insurance liabilities valuation first tends towards riskneutrality, which implies to consider a scheme where the societies future cash-flows are assessed under a structural fashion, omitting the conjectural aspect due to an overall (positive or negative) evolution of the market.

This specific kind of valuation is a clear switch compared to the first attempts of realistic (historical) valuation proposed in Europe (Traditional Embedded Value in the United Kingdom from the 80's, formalized in 2001, European Embedded Value 2004). It is also linked to a more or less explicit will to shape the European insurance regulation on the banking one (Basel II, III). The Solvency II perspective emerges. One can finally find numerous common points between the Basel and Solvency II regulations (see e.g. Schubert \& Grießmann (2004)): the use of the Value-at-risk as a risk measure, solvency and capital adequacy ratios, and so on... In a natural fashion, the imitation of practices drifts to the use of a risk-neutral valuation probability measure.

Note that, in practice, the IFRS norms implementation is today very far from the initially intuitive risk-neutral valuation scheme. Indeed, the complex world-oriented accounting homogenization was finally so difficult in insurance that the current practices tend towards a more basic adjustment of the previous local norms. In France, the IFRS liabilities are often adjusted from the former French GAAP (Generally Accepted Accounting Principles). Solvency II has chosen a different and probably more difficult pathway, that is to homogenize the European practices around the same risk-neutral valuation scheme. 


\subsubsection{From Solvency I to Solvency II}

In this subsection, a brief overview of the conceptual evolution of the European insurance regulation is provided.

The recent developments of the international solvency and accounting regulations share the same will to quantify and produce comparable benchmarks (see e.g. Desrosières (2008)). This is also present in both European insurance directives introduced by the European Commission since the beginning of the 2000's, Solvency I and II.

The first directive of the European Commission, Solvency I (2002), introduces the notion of solvency margin, the regulatory capital required for insurance companies to make business in one of the European states. Under these norms the capital is calculated as a percentage of the mathematical reserves. But this calculation process was not considered as optimal as the solvency measurement did not take the specific risk profile and the insurance contract characteristics of each company into account. Finally, in line with the development of the idea of fair value as a market value (IFRS) and the wide spreading of the valuation approaches by projection and discounting of future cash-flows (corporate finance), the European regulation has focused towards a scheme that better takes into account optionalities and time value of products. It considers two distinct aspects of the undertakings capital: what the company already disposes of (Revalued Net Asset), and what it is assumed to gain in the future (Value of In-Force). The latter is estimated as the expected sum of future discounted margin cash-flows of the products.

Under Solvency II (2009), this scheme becomes a standard and the main problem is the choice of the probability measure to perform this valuation. With the desire to be impartial and to homogenize the process through Europe, insurance market begins to talk about market valuation. The problem with historic valuation is that the model parameters (discount rate, risk premiums,...) are very complex to assess precisely and this leads to crucial homogenization problems. The idea is therefore to consider trading value: the parameters are observed on financial markets and easily available to each European insurance, which provides an efficient answer to impartiality. The valuation framework gets more precise: the models used to assess the products prices should be parametrized using the data given by financial markets. In addition, these markets generally valuate and disclose data under a risk-neutral probability measure, so the risks have to be projected under a risk-neutral probability.

However, not all risks factors of life insurance products are of financial nature (longevity, lapse,...). This is a problem because financial markets do not provide data for non-hedgeable risks. This issue is solved by considering only stochastic hedgeable risks. The valuation scheme focuses on financial risks. The non-hedgeable risks are managed separately through a cost-of-capital approach (see Floreani (2011)).

\subsubsection{Economic valuation and the economic balance sheet}

This foreword about regulation enables us to introduce the Solvency II-specific notion of economic value and the concept of economic balance sheet. This atypical balance sheet is, in its shape, quite close to the accounting asset and liability balance sheet. The liability side is generally separated between own funds and less liquid liabilities corresponding to the provision associated to the insurance liabilities towards its policyholders. 
The main difference with a standard accounting balance sheet is the methodology used to evaluate its various items. In opposite to the accounting standards, the economic balance sheet has to be fully valuated under a risk-neutral fashion. The obtained values are denoted as economic. This leads to the definition of the economic value of assets (their market value), of the liability portfolio (often denoted as the best estimate of liability), and finally, of the own funds. These values are expectations assessed under an actuarial valuation probability measure. The choice of this kind of valuation probability measure is an answer to the framework defined by the Solvency II directive.

Section 2 of the Solvency II directive, article 77.2 states that:

"The best estimate shall correspond to the probability-weighted average of future cashflows, taking account of the time value of money (expected present value of future cashflows), using the relevant risk-free IR term structure."

then,

"The calculation of the best estimate shall be based upon up-to-date and credible information and realistic assumptions and be performed using adequate, applicable and relevant actuarial and statistical methods."

The directive introduces here the requirement to choose a probability measure to assess the "probabilityweighted average of future cash-flows", and the idea of cash-flows discounting "using the relevant riskfree interest rates term structure". The existence or non-existence of a risk-free rate is a widely discussed subject. The risk-free rate is the return associated to an asset that does not support any risk of loss. Often required in theory (see Sharpe (1964) and Jensen, Black \& Scholes (1972) for capital asset pricing theories, see Solnik (1974) or Weil (1989) for the general equilibrium, Markowitz (1952) for portfolio selection, etc.), the risk-free rate, the existence of the risk-free asset, as well as the uniqueness under the no-arbitrage assumption are difficult to adapt in real market conditions. In corporate finance, the academics and practitioners have been facing this problem for a long time. Both regularly consider government rates term structures, but this presents two major defaults. Firstly, government bonds are far from being risk-free. Secondly, these rates are influenced by the local central banks choices concerning interbank rates. The users of such interest rates curves are both far from the zero-risk assumption and dependent of the exogenous choices of central banks. It is often accepted that swap rates are closer to risk-free rates than government bond rates while not being exempt of credit spread (see Delcour (2012) for insurance applications).

Considering the last regulation information, the process and parameters used to estimate the "relevant risk-free interest rates term structure" to be used by life insurance companies for economic valuations are provided and updated on a regular basis by EIOPA (European Insurance and Occupational Pensions Authority), so as to homogenize the economic valuation process. It is based on the Euroswap term structure but integrates various treatments to be adapted to each specific insurance market. Though this homogenization attempt of EIOPA may originally be a good idea, it also leads to new practical and theoretical issues. In particular, new difficulties happen when practitioners try to reconcile market prices with the regulatory interest rates term structure.

On the whole, in life insurance, the valuation process requires projecting and discounting of future cash-flows under a good probability measure. This probability measure is in practice (this is not fully 
explicit in the directive) a martingale measure associated to a numéraire that is the exponential integral of a regulatory risk-free rate, a measure that neutralizes other market trends, and therefore a risk-neutral probability measure.

In spite of its obvious theoretical gaps, this pragmatic valuation scheme is mostly scalable and adaptable to entity-specific actuarial practices.

\subsection{Economic valuation in practice}

\subsubsection{Economic scenarios \& market-consistency}

In practice any economic valuation process is implemented with Monte Carlo simulations to estimate the complex prospective behaviour of life insurance products options depending on the stochastic evolution of market risks. It is indeed almost impossible to assess closed formula for liability portfolios valuation, except without very strong model assumptions (see Bonnin, Planchet \& Juillard (2014)).

It requires actuarial practitioners to dispose of a table of valuation scenarios where the underlying financial risks are diffused under a good probability measure. In the economic valuation framework, this probability measure is said to be risk-neutral due to the fact that it is a martingale measure, where the numéraire is the exponential integral of the relevant risk-free interest rate diffused within the valuation table.

As explained in Subsection 2.1.2, the economic valuation framework requires to consider stochastic financial risks (stock, risk free interest rates, spread risk,...) and deterministic technical risks (mortality and longevity risks, lapse risk,...). It therefore needs the simulation of economic scenarios, composed with risk-neutral projections of the financial risks, the technical risks evolving through the valuation horizon according to deterministic chronicles (mortality rates, lapse rates per projection year) or as deterministic functions of the financial drivers outcomes (e.g. dynamic lapse), calibrated on historical data. The valuation table (an Economic Scenarios Table, EST) is obtained as a grouping of a sufficient number of these economic scenarios.

However there is still an issue with the choice of the risk-neutral probability measure to be used for the economic diffusion (the economic scenarios generation). Considering real market conditions, the inaccuracy of the market efficiency assumption leads to the existence of an infinity of risk-neutral probability measures under the numéraire chosen by the actuary. To objectify their measure choice, the companies have to add a selection criterion, based on so-called market-consistency.

This criterion is named by the Directive in Article 76:

"The calculation of technical provisions shall make use of and be consistent with information provided by the financial markets and generally available data on underwriting risks (market-consistency)."

The market-consistency notion has a deep but recent history within the actuarial literature (see Sheldon \& Smith (2004), Wüthrich, Bühlmann \& Furrer (2008), Malamud, Trubowitz \& Wüthrich (2008) or Moehr (2011)). On the whole it is possible to associate its first legitimation attempt, as far as its use 
through the European life insurance industry is concerned, to the book of Kemp (2009). This criterion is easy to handle under the complete market assumption. Indeed, in this simple scheme, the marketconsistent valuation of an asset is its unique trading value. The main difficulty of the market-consistency application appears when the complete market assumptions are not met. In an incomplete market, the idea of market-consistency valuation is to assess a best estimate of what its price should be if a complete market existed for its trade. This is exactly the statements introduced by Kemp:

"A market-consistent value of an asset or liability is its market value, if it is readily traded on a market at the point in time that the valuation is struck, and, for any other asset or liability, a reasoned best estimate of what its market value would have been had it been readily traded at the relevant valuation point."

According to current actuarial practices, the empirical application of the market-consistency requirement is to add a measure choice criterion based on the measured efficiency to replicate financial market prices. This is an example of actuarial interpretation that has nowadays a huge and systemic impact on the whole European life insurance market.

The objective of practitioners is finally to select / calibrate the valuation probability measure so that the EST generated under the chosen measure enables them to re-assess, by Monte Carlo valuations, options prices very closely to the prices observed on the financial market at the valuation date (at least for some well-chosen liquid derivatives). This market-consistent calibration is a source of practical difficulties and theoretical concessions, but it provides a straightforward valuation process. Actuarial practitioners deal with it through a five-step implementation, identifying probability measure selection with financial models calibration.

Sub-step a The practitioner chooses models to project any needed market variable (stock indices, interest rates, credit spreads,...). These financial drivers are selected so as to efficiently represent or summarize the company's liability portfolio underlying (financial) risk (e.g. for a French company, the chosen stock driver would be the CAC40 index). These models are market models that provide martingale scenarios under the chosen risk-neutral numéraire.

Sub-step b She selects some options and gets their prices or other market data, e.g. implied volatilities, on the market at the valuation date. These options prices / are used to calibrate the models selected through the first step (see Sub-step c).

Sub-step c She calibrates the financial models so that their parameters optimally fit these market data.

Sub-step d Using an Economic Scenarios Generator, she simulates a valuation EST, given the chosen models and calibrated parameters.

Sub-step e She checks the market-consistency of the obtained EST, that is its efficiency to re-estimate the calibration options prices. She also checks the martingale property of the discounted financial drivers, associated to the risk-neutral property of the EST.

In practice, the market-consistent (economic) values obtained strongly depend on the financial models and on the financial calibration data set (the options prices or volatilities) selected by the practitioners. 
In general the chosen data sets are quite consensual among practitioners, even if it is questionable that it is not always related to the set of hedging instruments purchased by the company. For example, one often chooses a set of at the money call and puts to calibrate the model used to project stock indexes (Black \& Scholes, Stochastic Volatility Jump Diffusion, Heston model,...). To calibrate the zero-coupon rate (or the instantaneous interest rate) model (Hull-White, Black-Karazinsky, Libor Market Model ${ }^{1}, \ldots$ ), one often uses a matrix of receiver swaptions implied volatilities or prices (for various maturities, tenors).

This implementation may lead to various homogenization issues as a certain degree of freedom is given to the companies to choose the financial models and the calibration data sets. They can greatly differ from one entity to another. Even the same model can be parametrized very differently when the calibration data set changes, especially because there exists almost one risk-neutral measure per financial asset due to the incompleteness of financial markets ${ }^{2}$. Similarly, a model change can breed large, unpredictable movements of the economic balance sheet items.

\subsubsection{Standard valuation process}

We have presented the way the valuation probability measure is selected and how financial models are calibrated. It is now possible to propose a standard three-step implementation process for an economic valuation aiming at assessing a best estimate of liability.

In Step 1, the company updates its Asset-Liability Management (ALM) hypotheses to reflect the economic reality. For the company this means updating its asset / liability portfolio, arbitrage law, financial strategy, commission rates, lapse and mortality assumptions,... but also getting the new economy parameters at the valuation date (new interest rates levels, implied volatilities,...).

In Step 2, the company chooses and calibrates its risk-neutral projection models. Then the practitioner simulates a large number of random economic scenarios at a 30 / 60 years horizon (the liability portfolio extinction horizon if no new business is added to the portfolio). This makes her get a risk-neutral EST which market-consistent efficiency is a posteriori checked.

In Step 3, using an ALM model, the company projects the liability cash-flows through the EST so that it obtains one cash-flow for each projection date (between $t=1$ and the chosen projection horizon) and for each economic scenario in the EST. The best estimate of liability is obtained as the average, on the set of valuation scenarios, of the net present (discounted) value of future liability cash-flows.

The process is very similar when the practitioner aims at valuating the economic own funds. The only difference lies in the projected cash-flows which are future margins cash-flows. The capital obtained as the expected net present value of future margins cash-flows is called the Value of In-Force (VIF). Then the economic own funds correspond to the sum of the Value of In-Force and the Revalued Net Asset (RNA).

\footnotetext{
${ }^{1}$ In reality this is a deeply insurance-specific form of Libor Market Model. In particular it is not used for its efficiency to project the Libor forward yield on very short horizons (a few days), which is its original objective, but to project zero-coupon curves on very long term horizon. For this reason, we denote this model by $L M M_{\text {ins }}$ below.

${ }^{2}$ See e.g. Mukerji \& Tallon (2001), Martin \& Rey (2004)
} 


\subsection{Comparative elements - financial vs. insurance practices}

At this point, it is relevant to compare insurance and finance practices concerning the use of risk-neutral valuation schemes. It is frequent, in Solvency II, to find inspiration sources from banking practices and regulation (see e.g. the very explicit paper of Schubert \& Grießmann (2004)). But it has to be noted that these two uses of risk-neutrality are different, sometimes opposed in their goal, conceptualization and management. This is clearly structural, due to the difference between these two businesses.

First, main objectives are different. Traders use the risk-neutral valuation to get fair trading prices, while actuaries estimate economic values for solvency purposes. They assess the economic value on a yearly basis for regulatory reasons, but there is no structural need for it to be a market value: it is not traded.

The second difference lies in the management of the risk-neutral valuation schemes. The market provides instantaneous data that change in a continuous fashion to adjust prices towards their true values. These data, implied volatilities in particular, are structurally made to change after every trade. The valuation measures also adjust trade after trade. In comparison, insurance undertakings only need one valuation per year to respond to the quantitative regulatory requirements. This leads to a great difference when apprehending the market data importance. When traders adjust their price continuously and are more interested by the historical movements, day after day, of market data, the actuaries valuate their yearly solvency capital need based on the single last trade of the year.

But the main difference between both approaches probably lies in hedging. Life insurance bears biometric and other technical risks that cannot be hedged. In opposition with bank trading practices, they do not hedge their products because there is no solution. Some insurers buy simple financial instruments (Caplets, Floorlets, Swaptions, Calls, Puts,...) to hedge a part of their asset portfolios against financial movements, but this is not true hedging. One has to remember that risk-neutral valuation is legitimated by hedging and requires hedging to be fully implemented.

There is little theoretical justification for insurance risk-neutral valuation. The risk-neutral valuation is intimately linked to a specific business and this leads to great difficulties when trying to switch from its original use. It is not adapted to the insurance industry and this leads to an atypical mix of practices, making it difficult and subjective to compare prices. The final framework is operationally complex for insurance practitioners. The consequences on valuation are impossible to quantify. The assessed values are difficult to justify and to check by control authorities. They are easy to manipulate by the biggest undertakings.

\section{Analysis of practical issues}

Various theoretical failures have been underlined through Section 2. One of the objectives associated to the Solvency II regulation is to make practitioners work by themselves to improve the process. The market should make its own law, through an healthy emulation and competition, then leading to economic optimality. In this section, we consider various practical issues induced by the current implementation of the directive. We analyze them and propose some first ideas to make the actuarial valuation scheme cleaner and safer. 


\subsection{Interest rates projection in the Economic Scenarios Generators}

Two major issues can be identified in the treatment used to forecast yield curves in the economic valuation framework. First the very complex practical scheme used to calibrate interest rates models embeds several malpractices that induce a great disconnection to fair pricing. Second, the use of risk-neutral market models leads to a deep lack in realism of the projected trajectories, that can have a great and unpredictable impact on the way the medium and long-term risks are taken into account in valuation.

\subsubsection{Calibration issues}

Let us consider a model-free calibration procedure, used in practice by most European life insurers. A refinement of Subsection 2.2.1 is required to better understand the model calibration sub-step. Assume the actuarial practitioner wants to calibrate its models on December 31 st of year N.

- On $12 / 31 / \mathrm{N}$ (the calibration \& valuation date) a matrix of at-the-money receiver swaption implied volatilities $(5 \times 510 \times 10,20 \times 20$, or limited to certain maturities / tenors) is obtained from a market data provider. In parallel, a reference zero-coupon (ZC) curve is provided by the EIOPA (adapted to date $12 / 31 / \mathrm{N}$ ). This curve is based on the Euroswap. To obtain the final regulatory-specific curve, a Credit Risk Adjustment spread (CRA) is subtracted to the re-compounded rates. The curve is now "risk-free". Then, a Smith-Wilson method is used to make the 1-year ZC forward rates converge towards a Ultimate Forward Rate (UFR) between maturity 20 years (the "Last Liquid point") and maturity 40 years. Finally a Volatility Adjustment (VA) treatment is applied on the $\mathrm{ZC}$ curve $^{3}$ which has to be used to assess economic valuations, in spite of the fact that it is not risk-free anymore. Thanks to these two inputs (ZC regulatory-specific curve and swaptions volatilities), they re-build swaption rates and prices (using Black formulas).

- In a second step, a model is chosen to project the yield curve ( $L M M_{\text {ins }}$, with stochastic volatility, 1 -factor Hull-White,...). A key decision criterion is the availability of a (sometimes approximated) closed formula for swaption prices, which must only depend on the interest rate curve and on the set of parameters required to simulate interest rates.

- Finally, an optimization algorithm is launched to minimize the distance between the theoretical swaption prices and the model swaption prices. Performing this algorithm leads the user to obtain the market-consistent model's parameters, as at date 12/31/N.

Interest rates risk is one of the major hazard source for life insurance, both under real life conditions and in economic risk management. This risk is however atypically managed in the economic valuation scheme. It induces several theoretical and practical issues.

It is known and understood in practice that each swaption is valued under a probability measure that is specific to its maturity and tenor. The knowledge of this measure is absolutely necessary to use the Black pricing formula and the provided implied volatility. The yield curve used to assess the swaption

\footnotetext{
${ }^{3}$ See EIOPA (2015) for the developments and justification of all these treatments used to formalize, in practice, the idea of "relevant risk-free interest rates term structure".
} 
rates, the numéraire values, and the final theoretical prices are not the right ones because the regulatory-specific yield curve does not enable practitioners to get the true swaption rates. The impact on final prices can lead to arbitrage sources. Indeed, the true swaption rates surfaces used on the market have a very specific shape that verifies some order conditions necessary to keep the no-arbitrage property. And this property is absolutely required to use or even calibrate a risk-neutral valuation.

In addition, consider the way market data providers (and Bloomberg, in particular) re-calculate the matrix of swaptions implied volatilities. In practice, not every swaption in the 10x10 matrix is traded each day and only some sets of maturities and tenors can be associated to trading prices and to "true" implied volatilities. For the other sets in the matrix, the providers use an algorithm (SABR for Bloomberg) to interpolate and extrapolate the other points in the matrix. Note also that some data used by actuaries are assessed by private firms and subject to exogenous expert judgment.

Finally, the choice of swaptions as calibration tools leads to a tricky problem. Indeed, when extracting data, a mismatch appears between the swaption rates disclosure time, corresponding to the true end of the trading day, and the swaption implied volatilities matrix disclosure time, corresponding generally to the last swaption trade. In practice, even financial practitioners have great difficulties to assess the exact swaption rate corresponding to an implied volatility. This leads to a structural impossibility to use any Black formula based on market data to re-obtain the good swaption prices.

The two last points are less problematic than the first one due to the heavy distortion observed in the yield curve induced by the CRA / UFR / VA application. These regulatory malpractices lead to an irrelevance of the final calibrated parameters.

But another strong issue is more structurally due to the use of risk-neutral interest rates models when projecting interest rates on the long term.

\subsubsection{On the importance of forward rates}

When market models are used to project yield curves, two major points have to be taken into account. First, the models are only used in financial markets for (very) short term simulations (e.g. 1 day / week). They do not provide a fair valuation of medium or long-term interest rate risk. This is due to the second important fact induced by their use: the simulation of flat curves in the long run.

The market models used by actuarial practitioners (1-factor Hull-White, $L M M_{\text {ins }}$, or others) all match the no-arbitrage property. Finally, let $F(t, s, \theta)$ be the $\theta$-year forward ZC price at time $s>t$, seen in $t \geq 0$. For simulated ZC curves, we have, under the t-forward measure,

$$
\forall \theta \in \llbracket 1 ; M \rrbracket, \mathbb{E}[P(t, \theta)] \simeq F(0, t, \theta)=\frac{P(0, t+\theta)}{P(0, t)} .
$$

The diffusion leads to a mixture between the forward ZC curve and a stochastic variation. Due to the reduced number of risk factors (between 1 and 3 in practice), the simulated curve either moves close to the forward curve or explodes. In the long run, the curves either explode or stay flat (due to the flat forward curve) close to 0 in order to compensate the numerous $L M M_{\text {ins }}$ exploding curves on average. This may have a limited impact on at the money or short term options pricing, but it can lead to a great mis-valuation of the medium and long-term time value of financial options and guarantees embedded in insurance products. 
Forward rates are important in every kind of market valuation. This is particularly true for economic valuations, where ZC curves can be projected through 60 and more years, for life insurance products such as pensions and savings products. It is remarkable that EIOPA discloses regulatory yield curves and adjustment methodologies / parameters (CRA / VA / UFR) which have a great impact on the final ZC curve, forward rates and on valuations. These market-inconsistent developments have little theoretical and practical legitimacy. They lead to a strong disconnection between insurance economic valuation and both true risk-neutral valuation or economic reality.

\subsubsection{Impact on economic scenarios}

To present the operational impact of the current economic valuation choices we have considered the yield curve explicitly given by the EIOPA at 12/31/14.

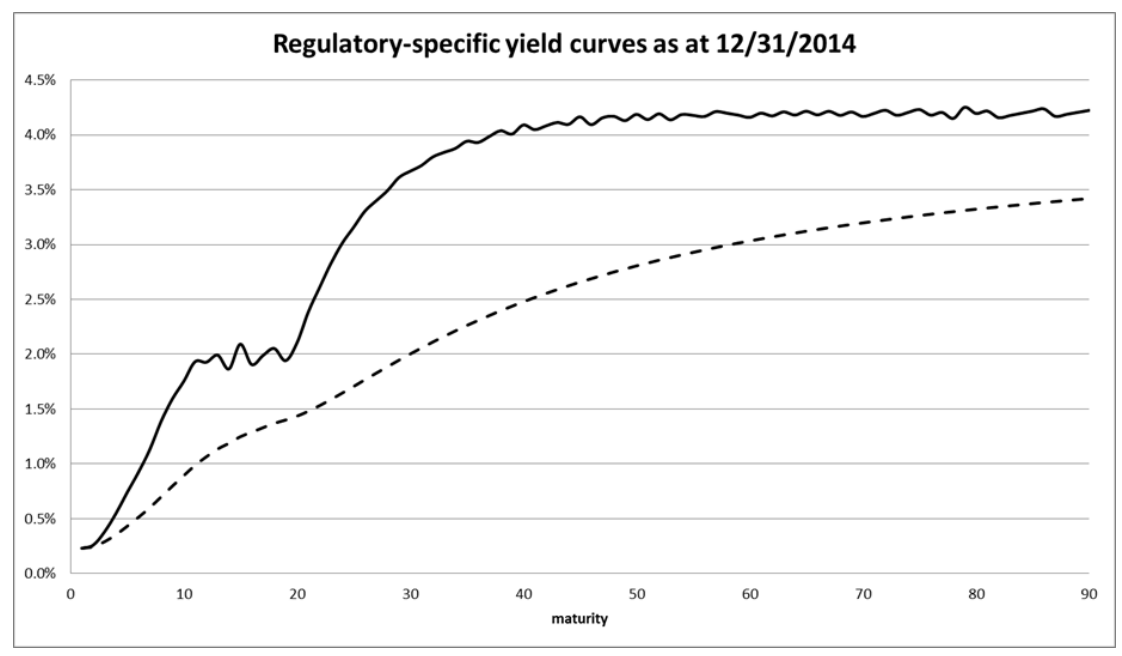

Figure 1: Yield curves at $t=0:$ ZC yield curve (dashed) and 1-year Forward curve (plain)

Figure 1 shows the regulatory-specific ZC yield curve by maturity (1 to 90 ) and the 1-year forward rates at $t=0(F(0, s, 1)$ for $s \in \llbracket 0 ; 90 \rrbracket)$. The yield curve lacks of realism mostly due to the UFR impact. In particular, the 1-year forward rates seen at $t=0$ present an erratic structure after 60 years (around the UFR, 4.2\%). This is structurally due to the Smith-Wilson methodology, and can be found on each and every regulatory yield curve. ${ }^{4}$ Another remarkable fact is the erratic form of the forward curve between maturity 10 and 20 (see the zoomed Figure 2).

This kind of forward curve is far from what can be observed in practice and specifically due to the EIOPA interpolation methodology.

Considering the swaption implied volatilities matrix at date 12/31/14 extracted from Bloomberg, we have calibrated a $L M M_{i n s}$ in a market-consistent fashion ${ }^{5}$. Then we have simulated 1000 random

\footnotetext{
${ }^{4}$ In most other practical fields, when using such a convergence algorithm, the erratic values after 40 years would be flattened by the user in order not to introduce any additional disturbance. It is remarkable that this is not made on the EIOPA yield curve.

${ }^{5}$ The $L M M_{\text {ins }}$ is only used here for illustration purposes. A pure finance practitioner may find many theoretical and practical
} 


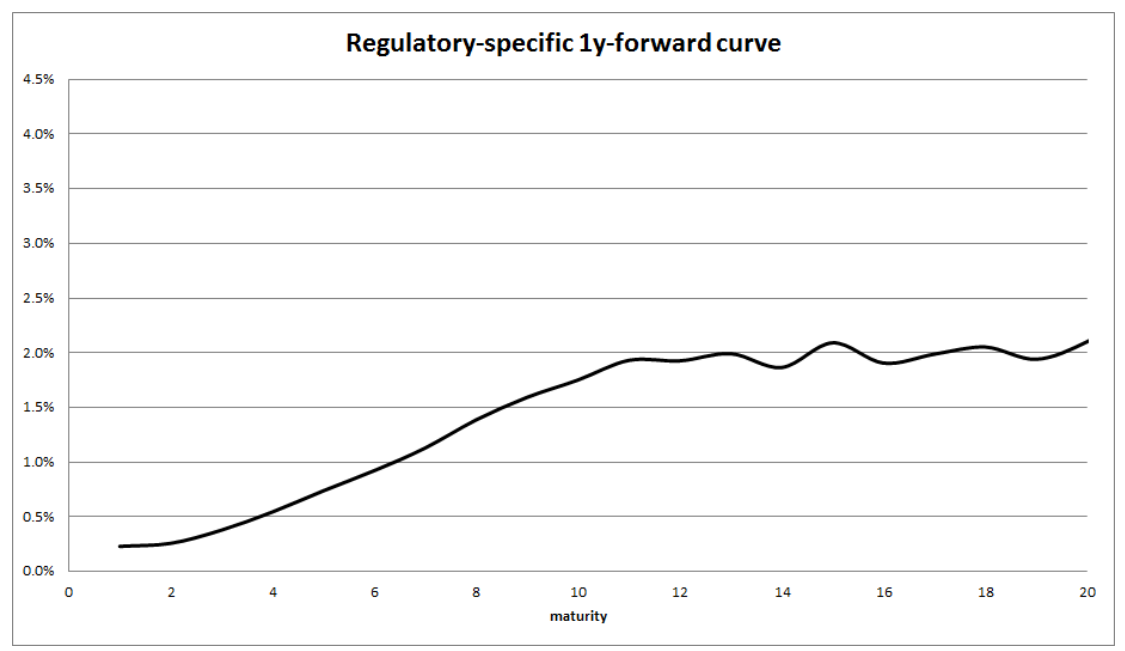

Figure 2: 1y-forward curve - zoom on maturities 0 to 20

trajectories of the yield curve on 30 maturities, through a time horizon of 60 years. ${ }^{6}$ As this model tends to produce explosive curves we have capped the yields at $70 \%$ in the Economic Scenarios Generator. This is a very typical market practice.

10 randomly drawn curves, simulated at time $t=10$ and $t=30$, are presented in Figures 3 and 4 . In addition we represent the corresponding forward yield curves as seen in $t=0$.

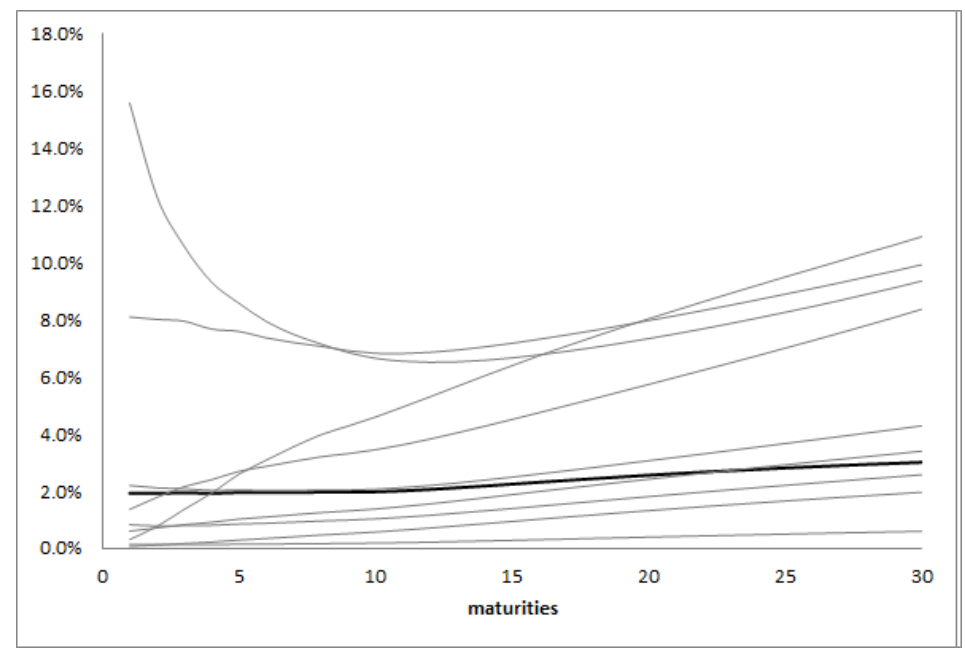

Figure 3: $\mathrm{t}=10 \mathrm{y}-10$ randomly drawn curves (grey lines) + forward curve at $\mathrm{t}=0$ (black line)

These two figures show the strong impact of the explosive rates. The cap is indeed reached for 5 issues when using this insurance adaptation of the natural $L M M$. This question is not developed here but will be addressed in further papers.

${ }^{6}$ We have chosen to consider a $L M M_{\text {ins }}$, because it is currently one of the mostly used model, but the results would be similar for other market interest rates models. 


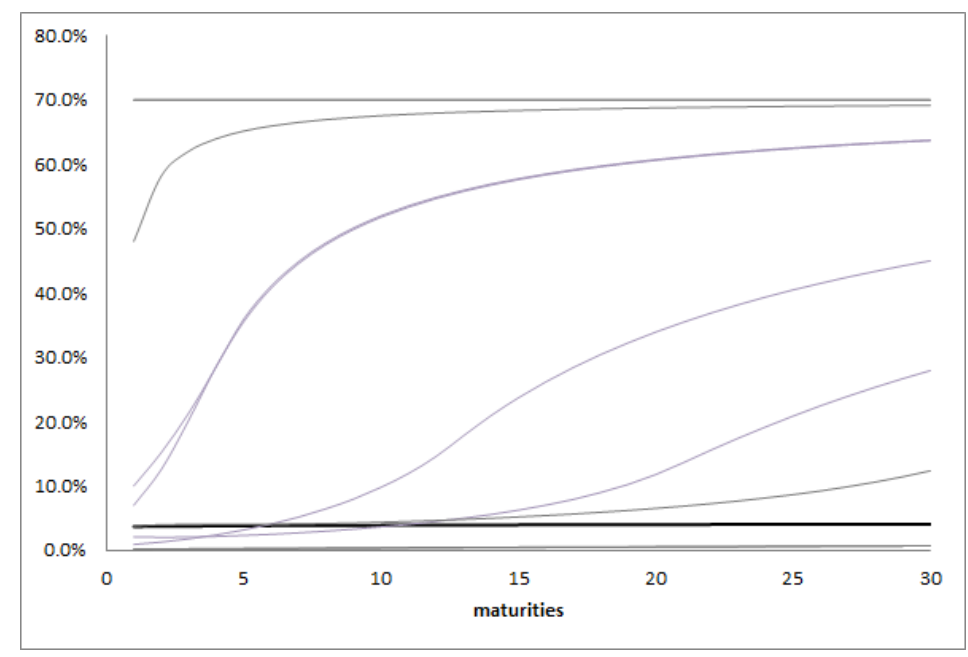

Figure 4: $t=30 y-10$ randomly drawn curves (grey lines) + forward curve at $t=0$ (black line)

out of 1000 simulations at $t=10 y$, for 75 out of 1000 simulations at $t=30 y$, and for 243 out of 1000 simulations at $t=60 y$. In practice, without any cap (here at 70\%), every yield either asymptotically goes to infinity or to $0^{7}$, which is a structural fact for the $L M M_{\text {ins }}$ and for most risk-neutral financial model (see El Karoui, Frachot \& Geman (1997), Dybvig, Ingersoll Jr \& Ross (1996)); this is one of the reasons why they are only used on a very short run by financial practitioners. In particular, we can wonder how policyholders and lapse rates would behave in such an unrealistic situation.

On the medium run, most curves are concentrated around the forward curve (see Figure 5 for $t=10 y$, where we have reported selected $20 \%$ of the simulated curves, chosen for their realism - no explosive rates / no flat and close to zero curves). It is structural for these risk-neutral models, every simulated curve at time $t=\theta$ years is deduced from the $\theta$ years-forward ZC curve as at $t=0$, on which the diffusion adds a time-increasing fluctuation based on a reduced number of random standard Gaussian outcomes.

As a conclusion on Subsection 3.1, we have shown the market inconsistencies appearing from the choice of swaptions implied volatilities data and from the regulatory-specific yield curve. In addition, we have presented and illustrated the fact that, though they embed a strong technical complexity to be calibrated and simulated, the risk-neutral models used by insurance undertakings to project interest rates follow similar and simplistic properties based on the replication of forward curves.

This illustrates the impact of adapting financial practices on completely different insurance topics. Simpler and more realistic models like the very intuitive Nelson-Siegel model are often used and studied by central banks (see e.g. the works of Söderlind \& Svensson (1997), Christensen, Diebold \& Rudebusch (2009) and Coroneo, Nyholm \& Vidova-Koleva (2011) for the European central bank). They provide realistic curves that could provide a much fairer valuation of insurance Time-Value of Future Options and Guarantees. But this model is not risk-neutral in the actuarial sense: all the actuarial models produce curves that are adapted from the forward ones and are therefore unable to provide a fair and comparable valuation.

\footnotetext{
${ }^{7}$ For the 10 randomly drawn curves shown in Figure 4 we already obtain 2 curves capped at $70 \%$ and 2 curves close to 0.
} 


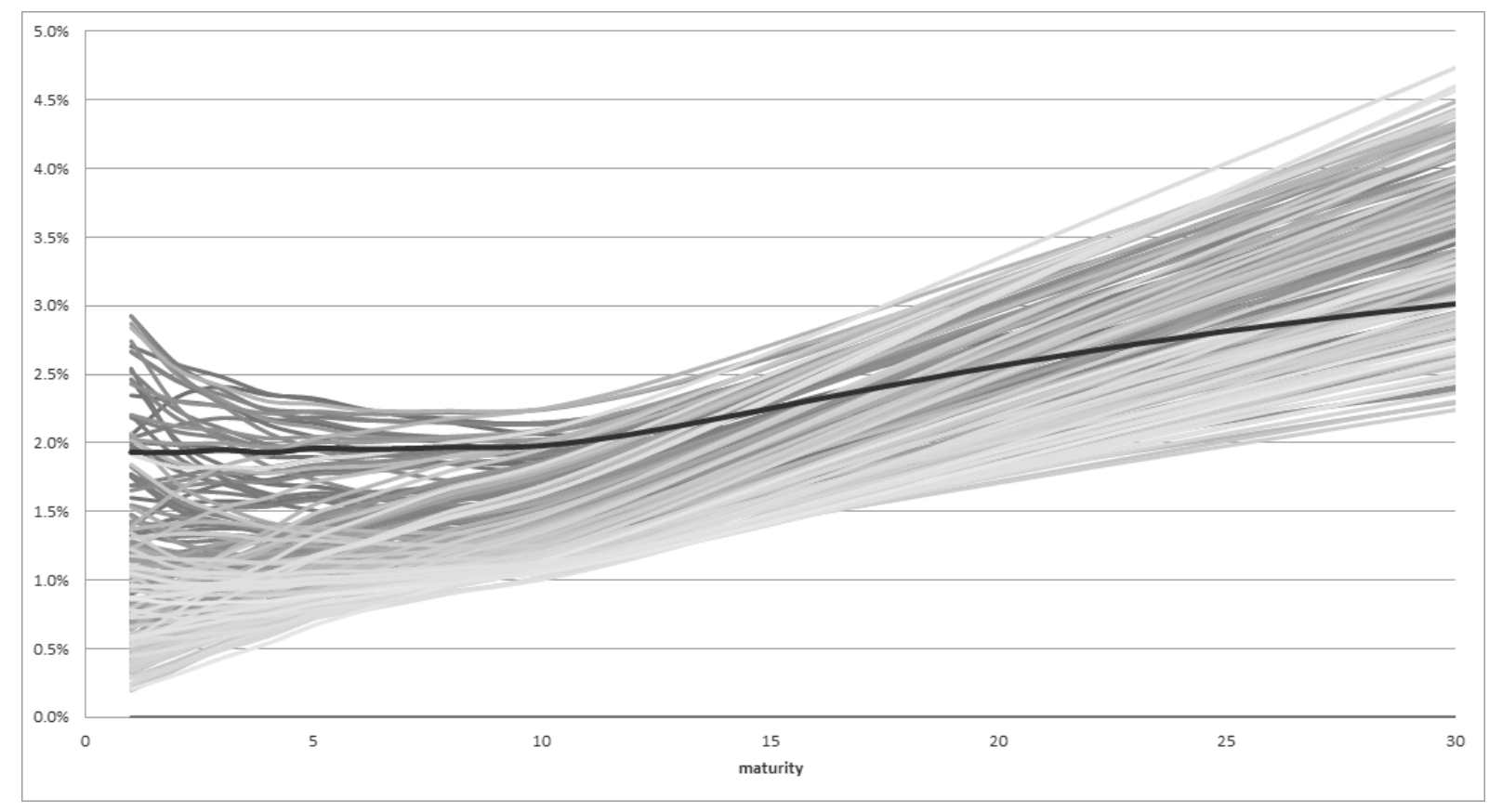

Figure 5: $\mathrm{t}=10 \mathrm{y}-$ Selected $20 \%$ of the simulated curves (grey lines) + forward curve at $\mathrm{t}=0$ (black line)

\subsection{The local character of market-consistency and the high volatility of economic valua- tion}

The actuarial market-consistency criterion leads to very volatile valuations. It is directly subject to market movements and depends on the calibration sets chosen by the actuary. We can therefore claim that this criterion is local in time and in space. In this Subsection, we develop this idea in order to underline the necessity for a strong shaping of these implementations, taking this locality into account in a better way.

\subsubsection{Locality in time and space}

What actuaries call market-consistent one day will have changed one day after. Financial markets move all the time; it is a structural property for environments where risk-neutral valuation is fairly used. This leads naturally to a high cyclicality of economic balance sheets and of economic own funds in particular.

- When everything goes fine on financial markets, stock prices tend to rise, interest rates have a "profitable" level, assets are liquid and implied volatilities are low. The economic own funds rise.

- But when the market is hit by a crisis, when it is unstable and illiquid, one observes high implied volatilities and the market drift switches to an adverse direction. Everything is going wrong and insurance companies undergo a decrease in their economic own funds (and in some cases a contingent rise of their capital requirements). 
This pro-cyclicality has led regulators to introduce counter-cyclicality valuation methodologies with mixed review. For more insight concerning these recent developments, one may read the various works concerning the liquidity premium (e.g. Danielsson, de Jong, Laeven, Laux, Perotti \& Wüthrich (2011), Danielsson, Laeven, Perotti, Wüthrich, Ayadi \& Pelsser (2012) and Delcour (2012)) first introduced in 2010, and concerning the currently used Volatility Adjuster (with the following document very recently published by EIOPA (2015)).

The local aspect of market-consistency also comes from a spatial component. Indeed, this criterion largely depends on the calibration data chosen to calibrate the models. Given the non-uniqueness of the risk-neutral probability measure, given the numerous approximations induced by the actuarial calibration of the models and given the numerous optionality sources embedded in the life insurance products, the market-consistent valuations can strongly vary if the users change the set of market data used to calibrate the market-consistent valuation probability measure.

This locality is also true in the space of the models used for the economic valuations. Indeed, for each economic drivers, numerous models are possible. All of them follow the same risk-neutrality properties but they provide very different time-values of insurance products. One can see such impact in the MarketConsistent Embedded Value (MCEV) reports that are disclosed by most listed firms. The MCEV is a market-consistent way to assess the embedded value of insurance firms (see CFO Forum (2009)). The valuation process is finally very close to the one used to assess economic own funds. The entities which calculate their MCEV also disclose a report that explains the deviations between their MCEV and its previous year value. This deviation can have numerous origins but one of them is called model changes in the report. According to those reports, it often leads to $10 \%$-deviations of prospective estimations, or even more.

\subsubsection{Impact of using market data as at the 12/31 on economic valuations}

Considering the locality in time, practitioners should also beware that the 12/31 is not the ideal date to calibrate a model with market data (and propose an insurance economic valuation). Indeed, at this date traders observe numerous unpredictable movements linked with the accounting closing date, leading to accounting optimization deals, sales and purchases of large positions. Markets are known to be specifically untrue, and to provide inexact, highly volatile prices and implied data on December. This well-known fact is supported by numerous analysis (see the numerous works on the December last trading day effect, e.g. Lakonishok \& Smidt (1988), Haugen \& Lakonishok (1988) or Chen \& Singal (2003)). It seems therefore quite hazardous to base a valuation framework on such data.

As an example, we present some statistics based on the implied volatility of the swaption of maturity $5 y /$ tenor $5 y^{8}$ in Figure 6. We have extracted the historical data associated to this volatility, from 10/01/14 to $01 / 31 / 15$. We show the evolution of the implied volatility and the 1-month moving volatility of this value, on historical data. December 14' is highlighted, in line with its erratic profiles.

Year 2014 gives a good idea of the impact of the local aspect of market-consistency and of the choice of calibration at 12/31 on the robustness of final outputs. It is well-known that economic values are highly driven by market cycles but when actuarial practitioners do a valuation they also give a high importance

\footnotetext{
${ }^{8}$ These parameters have been chosen because the receiver swaption of maturity $5 \mathrm{y} /$ tenor $5 \mathrm{y}$ is the most liquid one.
} 


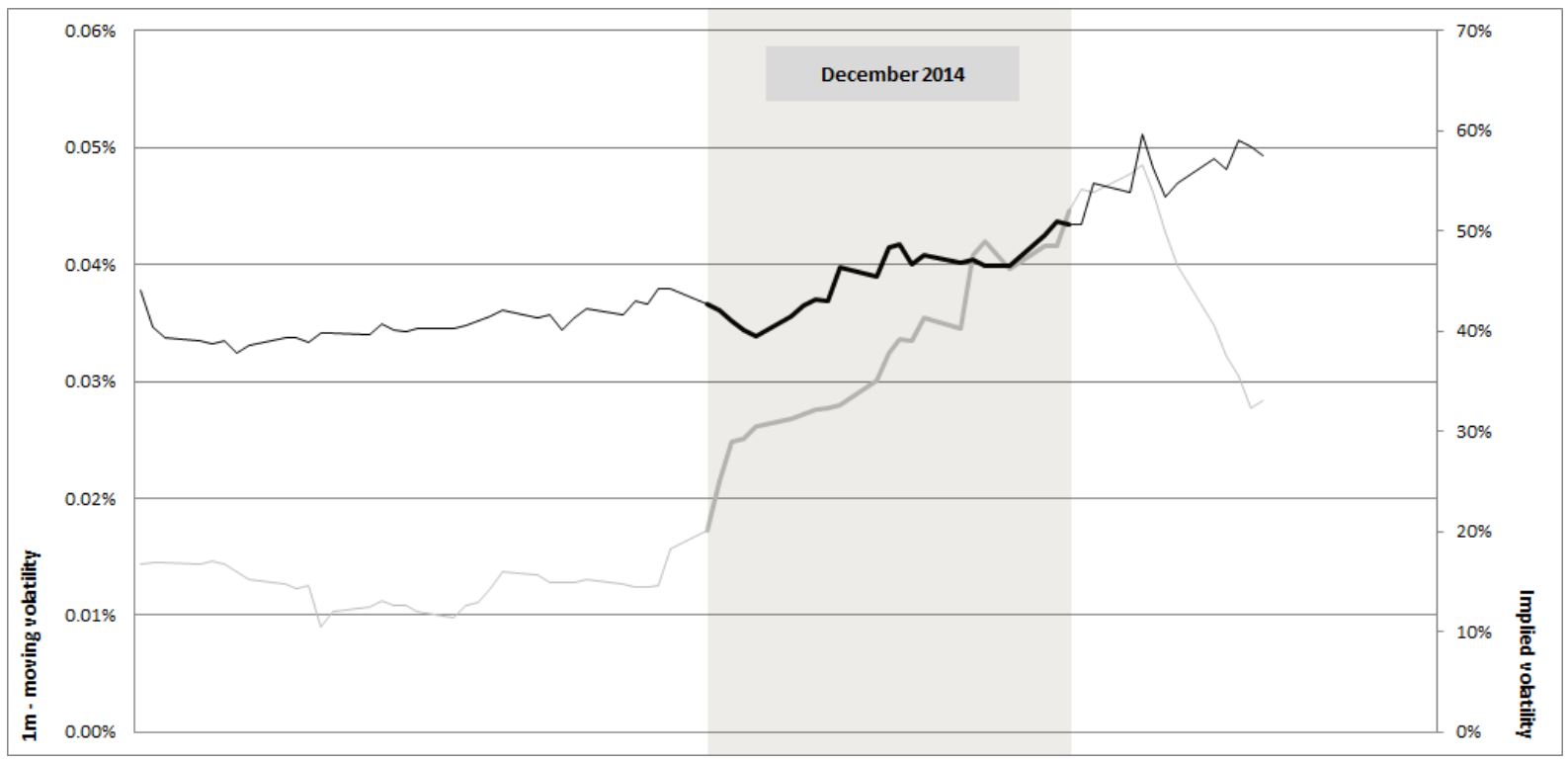

Figure 6: Statistics on the receiver swaption implied volatility - maturity $5 \mathrm{y} /$ tenor $5 \mathrm{y} /$ black line: $1 \mathrm{~m}$ moving volatility $10 / 15 / 14$ to $01 / 15 / 15$ - grey line: implied volatility $10 / 15 / 14$ to $01 / 15 / 15$

to non-expected accounting optimization malpractices. On the long run, the choice of a single date to calibrate data could even lead to additional insurance practices to optimize their economic values and required capital, such as buying or selling the appropriate assets.

Note that this is just a first illustration of the "turn of the year" effect. For more insight on the periodicity impact of this day on market data, the reader can find a wide range of papers on the subject (see Lakonishok \& Smidt (1988) and related literature).

\subsubsection{Alternative proposition}

To compute a more stable, framed, and robust economic valuation in life insurance using an adapted market-consistent constraint, an easily implementable approach could be to use averaged calibration data sets. As an example, we propose a calibration of the interest rates model (using a typical Libor Market Model) based on a replication of an averaged swaption implied volatilities matrix. Based on a realistic saving product, the valuation of the economic own funds is implemented for 4 types of calibration.

The first calibration is based on the implied volatilities matrix averaged on the whole month of October 2014. Only the receiver swaptions of maturity 5, tenors 1 to 10 , and the receiver swaptions of tenor 5, maturities 1 to 10 are used in the calibration set, to focus on the most liquid options.

The second calibration is based on the implied volatilities matrix averaged on the whole months of October and November 2014. Only the receiver swaptions of maturity 5, tenors 1 to 10, and the receiver swaptions of tenor 5, maturities 1 to 10 are used in the calibration set, to focus on the most liquid options.

Two different valuations are made at 12/31/14. Both of them can be considered as market-consistent 
but are performed using different sets of calibration assets: for the third calibration, we use the receiver swaptions of maturity 10 , tenors 1 to 10 , and the receiver swaptions of tenor 10 , maturities 1 to 10 (v1). For the fourth calibration, we use the receiver swaptions of maturity 5 , tenors 1 to 10 , and the receiver swaptions of tenor 5, maturities 1 to 10 (v2).

The final results, obtained thanks to a 30-year EST of 1'000 random simulations ${ }^{9}$ initialized with the same seed, are presented in Table 1.

Table 1: Comparison between the obtained economic own funds value

\begin{tabular}{|c|c|c|c|c|}
\hline & October 14' & Oct. \& Nov. 14' & $12 / 31 / 14$ v1 & $12 / 31 / 1$ \\
\hline $\mathrm{eco}$ & $16 ’ 898$ & $15^{\prime} 614$ & 7’046 & $10 ’ 000$ \\
\hline
\end{tabular}

Several interesting points can be raised. The locality in time is well illustrated by the great difference between 12/31 and October / November values (around 100\% relative difference). The locality in space is highlighted by the strong difference between $\mathrm{v} 1$ and $\mathrm{v} 2$ valuations (more than $40 \%$ relative difference). The stronger decrease associated to calibration $\mathrm{v} 1$ can have various sources. We have seen in Subsection 3.2.2 that the implied volatilities have globally increased between 10/01/14 and 12/31/14. In addition, the considered product may have various specific characteristics that make the shape of v1 $L M M_{\text {ins }}$ interest rates volatilities (long term versus short term) more adverse than the analogue for v2.

Using averaged data breeds more stability. The two economic valuations calibrated on averaged implied volatilities only differ by around $8 \%$. One should note that such implementations have already been made by practitioners during the most impacting years of the 2007 financial crises. But the process has been left apart to refocus on market data at 12/31.

The numbers in Table 1 were obtained for a representative French life insurer. One could think that the observed differences are amplified by the portfolio structure. To be reassured, we have run the same analysis on two other real life portfolios, with the following characteristics :

- A $2^{\text {nd }}$ standard savings product, which asset embeds stocks (13\%), bonds (86\%) and cash (2\%). The ALM model embeds a profit sharing rule, a minimum guaranteed rate, dynamic lapse,...

- And a $3^{\text {rd }}$ saving product, which asset embeds stocks (22\%), bonds (77\%), a little bit of cash and a few derivatives $(<1 \%)$. The ALM model still embeds the usual asset and liability management rules.

We obtain similar results (see Table 2) which shows that this phenomenon is not limited to a particuliar portfolio type.

\subsubsection{The manipulation issue}

Another relevant issue illustrated in Subsection 3.2.3 is the opportunity for insurers to manipulate the market-consistency and economic values.

\footnotetext{
${ }^{9}$ The choice of 1'000 scenarios is an averaged number of simulations among European life actuarial practitioners. It would of course be desirable to use many more simulations.
} 
Table 2: Comparison between the obtained economic own funds value - additional tests

\begin{tabular}{|c|c|c|c|c|}
\hline & October 14' & Oct. \& Nov. 14' & $12 / 31 / 14 \mathrm{v} 1$ & $12 / 31 / 14 \mathrm{v} 2$ \\
\hline portfolio nb 2 & $12 ׳ 826$ & $12 ’ 283$ & 9'517 & $10 ’ 000$ \\
\hline portfolio nb 3 & $12 ’ 553$ & $12^{\prime} 073$ & $6 ’ 050$ & $10^{\prime} 000$ \\
\hline
\end{tabular}

Indeed, a re-allocation of assets and the corresponding switch in the asset portfolio duration could be an easy justification to switch from (v1) to (v2). In practice it is very likely that this switch, justified by the new asset portfolio and still leading to an efficient market-consistency of the valuation, would be accepted by the local supervisor. For the insurer, the impact is immediate: a 40\%-increase in its net asset value.

Other manipulations, such as financial model changes, are possible. Indeed, an undertaking can test several interest rates models that are all accepted by the control authority. It could be tempting to select the one that provides the best results.

Finally, the notion of market-consistency being currently based on 12/31 market data, it is imaginable that, in the future, a big company that understands market finance enough optimizes its relevant swaption volatilities values, through the buying and selling of swaptions. This kind of finance manipulations has already been observed (see among others Abrantes-Metz, Kraten, Metz \& Seow (2012), Abrantes-Metz, Villas-Boas \& Judge (2011)).

To limit these manipulation opportunities, regulators could impose restrictions on the calibration sets and simulation models. Another possibility could be to simply use averaged data based on 1 or 2 months, such as Subsection 3.2.3 proposed alternatives. This kind of practice would make market manipulations more difficult because of the averaged data inertia.

Practitioners should also better objectify their valuation choices, by linking in a better way marketconsistency, models, calibration sets, financial modeling choices and insurance product specificities. A first alternative to improve this point is presented in Subsection 3.3.

\subsection{The entity-specific aspect of valuation}

In Subsection 3.3, we address a specific point regarding current actuarial practices. This could lead to an improvement in the objectification of the valuation probability measure and enable one to better take into account the local aspect of market-consistency.

\subsubsection{Operational valuation practices}

In Section 2, we have seen that there exist several potentially subjective choices through the selection of the valuation probability measure (e.g. the choice of the financial models, of the calibration set,...). These choices are objectified by the requirement that the valuation scheme must efficiently fit the economic environment of the entity. As an example, a firm highly subject to the French economy variations chooses the $\mathrm{CAC} 40$ as its reference stock index and the corresponding at the money options (Calls/Puts on the $\mathrm{CAC} 40, \ldots)$ as calibration assets for its financial models. The chosen assets depend on the models to 
calibrate but most companies use similar calibration sets. The calibration framework is indeed mostly homogeneous due to two facts. First, EIOPA has developed standardized methodologies to calibrate the Standard Formula shocks (see e.g. Bruss. (2010)), based on standard calibration sets of assets. These sets have become standards and are often used by the insurance stakeholders to calibrate their financial models. Second, the major economic scenarios provider, Moody's analytics (formerly known as Barrie $\&$ Hibbert) has developed software, financial models and calibration methodologies that tend to become standards for their clients and for the European life insurance market.

From a more general point of view, the current implementations lead to entity-specific valuation frameworks. Indeed, the companies calibrate, once and for all, the financial models they plan to use to valuate the economic balance sheet associated to all of their life insurance products (or one set of models for every product sold under the same economy). This results in the use of only one valuation probability measure for all life insurance products (or one per economy). The process and the values obtained are therefore more entity-specific than product-specific.

As it does not take the specific characteristics of the valuated products into account, this aspect of valuation leads to great difficulties when comparing the economic values of similar products which are estimated by different companies. Comparability (like objectivity) is however a key factor for efficient regulation. But here, the local character of market-consistency is not taken into account when assessing economic values and this can lead to great divergences and comparison difficulties when estimating the economic values.

In Subsection 3.3.2 and 3.3.3, we present the potential impact of these implementation choices and propose an alternative probability measure selection approach.

\subsubsection{Local Market Consensus Probability Measure}

In the banking industry, consider two different complex financial assets on a standard risk, for example an American Call and an American Put options on the Dow Jones index, with different maturities and moneynesses. Assume that a Monte Carlo approach is used to valuate these two hedgeable options using similar financial models. Under these assumptions, the parameters of the two models used in the two Monte Carlo processes should be very different because the market for such options is illiquid and incomplete, and because one part of the parameters choice process requires (subjective) expert trader judgment.

Life insurance products are much more complicated and much less liquid than those two assets. It seems therefore necessary to consider product-specific (or at least ring-fence-specific ${ }^{10}$ ) parameters, which leads to the consideration of a much more locally market-consistent valuation probability measure.

We propose therefore to consider a more locally defined market-consistency criterion. Insurance undertakings should take account of the very own characteristics of their products when they are up to

\footnotetext{
${ }^{10}$ Through the Solvency II implementation scheme, products are grouped in ring-fences and most economic valuations are in fact applied to ring-fences of products. We always speak of valuating products, for the sake of simplicity, but the LMCPM approach developed here (and implemented below), can easily be extended, without loss of generality, to ring-fences of products / liabilities valuations, which may be more useful to practitioners. In particular a ring-fenced LMCPM measure still leads to a more local and adapted market-consistency than a standard valuation approach where each ring-fence of life insurance products is valuated under the same probability measure.
} 
economically valuate them. As exact market-consistency is impossible to reach, more attention should be paid to the choice of the asset sets used to calibrate the financial models chosen by the entity. Some standard characteristics of life insurance products can easily be taken into account. The liability duration and convexity, the portfolio used to protect the product against financial movements (if it exists, which is not frequent in the European life insurance market due, among others, to the cost of such portfolios in terms of Solvency Capital Requirement in Solvency II), as well as the portfolio of assets used to face insurance liabilities are good examples of such data. In general, one should consider a different calibration set for each economic valuation. There exists almost one different risk neutral probability measure for each complex financial asset valuation; similarly, there should exist one different risk neutral probability measure for each life insurance liability (or ring-fence of liabilities) valuation.

This is a first proposition to refine the calibration process used by practitioners. This alternative approach leads to use a more locally adapted valuation measure, a Local Market-Consensus Probability Measure (LMCPM or more simply, LMC). Through Subsection 3.3.3, we propose a LMC approach implementation and study the difference in valuation observed between the standard framework and this alternative, for a real life insurance product.

\subsubsection{Case study}

We adapt the LMC approach to a real savings product. This product shows all the characteristics of a standard French savings contract, embedding optionality (implemented using dynamic lapses, taking profit-sharing rules and minimal guaranteed rate rules into account), and a fine granularity of policyholders. Its asset portfolio is composed of standard and inflation-linked bonds, stocks, OPCVM, hedge fund and property indexes, in two different currencies, US dollars and Euros. As it is a French product and mostly impacted by changes in the Euro zone markets, we chose the relevant risk-free interest rates term structure to be the Euroswap curve (no CRA / VA / UFR). We do not use the regulatory-specific curve in this subsection, to avoid adding any noise on the true LMC impact. We believe this choice has little impact on our analysis. The valuation is processed as at 12/31/2013.

Implementation As only interest rate risk is hedged, we only project stochastically this one. The other risk factors (stock, OPCVM, hedge fund and OPCVM indexes, US dollar currency bonds and indexes) are assumed to be deterministically capitalized at the forward rate observed as at the valuation date. The only financial model used to stochastically project the risks is the Euroswap interest rates model, a $L M M_{\text {ins }}$. The difference between the standard calibration and the LMC approach lies in the $L M M_{\text {ins }}$ parameters obtained through the calibration process, either replicating a standard (10 maturities x 10 tenors) matrix of at-the-money receiver swaption implied volatilities or the ones of the protection portfolio.

\section{Results}

The $L M M_{\text {ins }}$ enables us to estimate the prices of at the money swaptions, using efficient approximations (see Hull \& White (2000)). Note that, in our implementation, we have chosen to price the swaptions and initialize our simulations using the Euroswap curve as at 12/31/13 without the CRA / VA / UFR ad- 
justment in order to clean the calibration / simulation process (see Subsection 3.1.1). We believe that this choice has little consequence on the potential impact of the LMC approach on valuation. We have implemented and compared two approaches.

- The methodology used by practitioners to calibrate their $L M M_{\text {ins }}$ is depicted in Subsection 3.1.1). In a standard implementation, we have implemented this methodology based on the replication of a swaption implied volatility matrix, for maturities from 1 to 10 and tenors from 1 to 10 , obtained as at December 31st, 2013.

- Protected life insurance products, as far as interest rate risk is concerned, use receiver swaptions but also caps and floors. However, as most interest rate models are calibrated based on the replication of swaptions volatilities, we have chosen in a LMC application to replicate only the swaption protection portfolio. The swaptions weights are integrated in the least squares calibration program.

The estimated economic own funds (OF) can be divided into two parts: the Revalued Net Asset (RNA, corresponding to the capital already earned by the firm), and the Value of In-Force (VIF, corresponding to the average of the net present value of future margins). In practice, the VIF is the only one impacted by the $L M M_{\text {ins }}$ calibration process. We give below the decomposition of the economic own funds obtained considering the standard calibration process. The VIF is estimated according to the process developed in Subsection 2.2.2, based on only 1'000 economic scenarios due to the time-consuming character of this implementation.

Table 3: Comparison between the obtained economic quantities

\begin{tabular}{l|l|l|l}
\hline Economic values & \multicolumn{1}{c}{ Standard valuation } & \multicolumn{1}{c}{ LMC approach } & Relative deviation \\
\hline OF & 2'069 & 2'113 & $2.1 \%$ \\
RNA & 1'000 & 1 '000 & $0.0 \%$ \\
VIF & 1'069 & 1 '113 & $4.1 \%$ \\
\hline
\end{tabular}

\subsubsection{Analysis of the results and limits of our proposition}

The final economic own fund values are estimated based on 1'000 economic scenarios. Though the number of scenarios used in this case study is limited, the Monte-Carlo estimators of the VIF have small volatility (lower than $30 \%$ of the estimated expectancies) and the LMC VIF is significantly higher (at a $5 \%$ confidence level) than the standard VIF. The observed deviation is small but this can be associated to the fact that this product's asset portfolio is not fully composed with interest rate products. It also embeds stock, OPCVM, property and hedge fund indexes. Note that, due to the complex link between the calibration process and the assessed economic values, it is almost impossible to predict the impact of switching from the standard approach to the LMC approach. In this LMC implementations, we can see that the LMC method has a small but significant impact. However, the locality in space depicted in Subsection 3.2.3 illustrates well the potential impact induced by the LMC methodology.

We have chosen several simplification hypotheses that may have reduced the impact of the LMC approach. For example, we have applied the methodology in a scheme where only interest rates are 
stochastic. In general, one should use a more general protection portfolio. Due to cumulative effects, it is likely that the difference in valuation would have been bigger if all financial risks (stock, hedge fund, OPCVM, property risks,...) were stochastically projected and calibrated through our alternative methodology.

\section{Conclusion and policy recommendation}

In this paper, we have replaced the European actuarial risk-neutral (economic) valuation scheme in its context. We have shown, in particular, how the incompleteness of financial markets and the associated non-uniqueness of the risk-neutral probability measure drive actuarial practitioners to add a complex selection criterion when defining their valuation probability measures, market-consistency. The final valuation process makes use of the risk-neutral paradigm in an unadapted context. From this point, we have exemplified some of the main pitfalls of the actuarial practices. This has led us to re-focus on the true goals of the European regulation. The first objective is to control the systemic risk embedded in European life insurance. The second one is to provide an objective valuation scheme adaptable to a large set of different countries and market specificity, and most of all easily controllable. The third one is to enable a full-comparability of the valuations. The second point, though the current scheme leads to great theoretical issues and control difficulties, seems to have been more or less fulfilled. Concerning the third point, we think that more could be done because of the great subjectivity of the final economic values. European authorities could give additional directions; alternative implementation methods could be proposed; the regulation scheme could be simplified. Although the new directive carts very interesting new ideas (including the will to estimate the time-value of insurance product and to develop a scheme adaptable to the specific characteristics of the companies), one must limit the manipulation sources induced by the current process and the importance given to external, unsupervised data providers.

The main conclusions of our study can be summarized in two warning points.

First, risk neutrality used for long term projections simply leads to a lack of realism that can imply severe misvaluations and impact the real accounting solvency of the undertakings. Not taking market trends into account, it considers a case that artificially over-penalizes asset management and protection. The major problem is that it more or less directly concerns solvency, systemic risk, and customers.

Second, market-consistency leads to potential manipulation of values. It allows many entity-specific choices such as models and calibration sets, leading to a high volatility and non-comparability of the economic values (Solvency Capital Requirement included). In addition, the choice of the turn-of-theyear to select the data used to assess regulatory capital and other economic valuations is dangerous due to the specific untrue and volatile data available on financial markets at this date. In this framework, the work of supervisors is outstandingly challenging.

Concerning these two points, our policy recommendations are the following.

Risk-neutrality is barely adaptable to life insurance liabilities. The will to impose and legitimate economic valuation has led to successive adjustments (e.g. CRA / VA / UFR). They are difficult to justify in practice and lead to an over-complexification of the directive application. This should not let the market actors forget the true objective of the directive. Realism is a key element to evaluate the efficiency of any market to face systemic risk. As far as life insurance is concerned, this can be applied 
simply by adapting more realistic models (accepting to get out of the risk neutral paradigm, to create an insurance-specific one) or limiting the projection of data to only 5 or 10 years. The idea behind these refinements is clear: to catch the real impact of risks. Further works are clearly necessary to quantify the impact of this lack of realism and to propose alternative implementations.

We have presented first possibilities to set the market-consistent character in a cleaner fashion, in particular by restoring the link between the insurance product properties and the Economic Scenarios Generator choices (models and used calibration sets). The current processes used to calibrate models prove to provide, once fully understood, unstable and manipulable results. Concerning this point, a first improvement could be to use new, more stable calibration data sets (averaged data based on 1 or 2 months) or methodologies (the LMCPM process), or new models that produce more realistic simulations.

Finally, this study breeds various research perspectives. Concerning the issues raised in the paper, we have simply pointed out first alternative possibilities to standard economic valuation implementations, but it would be necessary to deeper analyze the possibility to implement these propositions and their operational impact. It would also be interesting to consider more general alternatives and in particular refine, reshape in a finer fashion, the market-consistency criterion. It would also be relevant to refocus the regulator's mind on the very objective of the directive, a reduction of the systemic risk. The complexity of the defined scheme seems to have left this goal apart for the sake of legitimacy. In practice, it is likely that sensitivity analysis under realistic conditions could have greater impact than this $99.5 \%$ Value-at-Risk estimation, especially under non-realistic assumptions.

\section{References}

Abrantes-Metz, R. M., Kraten, M., Metz, A. D. \& Seow, G. S. (2012), 'Libor manipulation?', Journal of Banking \& Finance 36(1), 136-150.

Abrantes-Metz, R. M., Villas-Boas, S. B. \& Judge, G. (2011), 'Tracking the libor rate', Applied Economics Letters 18(10), 893-899.

Becherer, D. \& Davis, M. H. (2008), 'Arrow-debreu prices', Encyclopedia of Quantitative Finance .

Bingham, N. H. \& Kiesel, R. (2004), Risk-neutral valuation: Pricing and hedging of financial derivatives, Springer.

Black, F. \& Scholes, M. (1973), 'The pricing of options and corporate liabilities', The journal of political economy pp. 637-654.

Bonnin, F., Planchet, F. \& Juillard, M. (2014), 'Best estimate calculations of savings contracts by closed formulas: application to the orsa', European Actuarial Journal 4(1), 181-196.

Bruss. (2010), 'Quantitative Impact Study 5 - technical specifications'.

CFO Forum (2009), 'Market consistent embedded value principles'.

Chen, H. \& Singal, V. (2003), 'A december effect with tax-gain selling?', Financial Analysts Journal 59(4), 78-90. 
Christensen, J. H., Diebold, F. X. \& Rudebusch, G. D. (2009), 'An arbitrage-free generalized nelsonsiegel term structure model', The Econometrics Journal 12(3), C33-C64.

Coroneo, L., Nyholm, K. \& Vidova-Koleva, R. (2011), 'How arbitrage-free is the nelson-siegel model?', Journal of Empirical Finance 18(3), 393-407.

Danielsson, J., de Jong, F., Laeven, R., Laux, C., Perotti, E. \& Wüthrich, M. V. (2011), 'A prudential regulatory issue at the heart of Solvency II', VOX Policy Note, March .

Danielsson, J., Laeven, R., Perotti, E., Wüthrich, M., Ayadi, R. \& Pelsser, A. (2012), 'Countercyclical regulation in Solvency II: Merits and flaws', VOX: Research-based Policy Analysis and Commentary from leading Economists 2012(23-06-2012).

Delcour, I. G. (2012), On the use of risk-free rates in the discounting of insurance cash flows, $\mathrm{PhD}$ thesis, KATHOLIEKE UNIVERSITEIT LEUVEN.

Desrosières, A. (2008), L'argument statistique: Pour une sociologie historique de la quantification, Presses des MINES.

Devineau, L. \& Loisel, S. (2009), 'Construction d'un algorithme d'accélération de la méthode des "simulations dans les simulations” pour le calcul du capital économique Solvabilité II', Bulletin Français d'Actuariat 10(17), 188-221.

Dybvig, P. H., Ingersoll Jr, J. E. \& Ross, S. A. (1996), 'Long forward and zero-coupon rates can never fall', Journal of Business pp. 1-25.

EIOPA (2015), 'Eiopa publishes Solvency II relevant risk free interest rate term structures'.

El Karoui, N., Frachot, A. \& Geman, H. (1997), 'On the behavior of long zero coupon rates in a no arbitrage framework', Review of derivatives research 1, 351-370.

Floreani, A. (2011), 'Risk margin estimation through the cost of capital approach: Some conceptual issues', The Geneva Papers on Risk and Insurance-Issues and Practice 36(2), 226-253.

Glasserman, P. (2004), Monte Carlo methods in financial engineering, Vol. 53, Springer.

Haugen, R. A. \& Lakonishok, J. (1988), 'The incredible january effect: The stock market's unsolved mystery (dow jones-irwin, homewood, il)', HaugenThe Incredible January Effect: The Stock Market's Unsolved Mystery1988.

Hull, J. C. \& White, A. (2000), 'Forward rate volatilities, swap rate volatilities, and the implementation of the Libor Market Model'.

Jäckel, P. \& Bubley, R. (2002), Monte Carlo methods in finance, J. Wiley.

Jensen, M. C., Black, F. \& Scholes, M. S. (1972), 'The capital asset pricing model: Some empirical tests'.

Kemp, M. (2009), Market Consistency: Model Calibration in Imperfect Markets, John Wiley \& Sons. 
Kreps, D. M. (1981), 'Arbitrage and equilibrium in economies with infinitely many commodities', Journal of Mathematical Economics 8(1), 15-35.

Lakonishok, J. \& Smidt, S. (1988), 'Are seasonal anomalies real? a ninety-year perspective', Review of Financial Studies 1(4), 403-425.

Malamud, S., Trubowitz, E. \& Wüthrich, M. V. (2008), 'Market consistent pricing of insurance products', ASTIN Bulletin-Actuarial Studies in Non Life Insurance 38(2), 483.

Markowitz, H. (1952), 'Portfolio selection', The journal of finance 7(1), 77-91.

Martin, P. \& Rey, H. (2004), 'Financial super-markets: size matters for asset trade', Journal of International Economics 64(2), 335-361.

Merton, R. C. (1971), 'Theory of rational option pricing'.

Moehr, C. (2011), 'Market-consistent valuation of insurance liabilities by cost of capital', Astin Bulletin 41(02), 315-341.

Mukerji, S. \& Tallon, J.-M. (2001), 'Ambiguity aversion and incompleteness of financial markets', The Review of Economic Studies 68(4), 883-904.

Schubert, T. \& Grießmann, G. (2004), 'Solvency II = Basel II+ X', Versicherungswirtschaft 18, 13991402 .

Sharpe, W. F. (1964), 'Capital asset prices: A theory of market equilibrium under conditions of risk', The journal of finance 19(3), 425-442.

Sheldon, T. J. \& Smith, A. D. (2004), 'Market consistent valuation of life assurance business', British Actuarial Journal 10(03), 543-605.

Söderlind, P. \& Svensson, L. (1997), 'New techniques to extract market expectations from financial instruments', Journal of Monetary Economics 40(2), 383-429.

Solnik, B. H. (1974), 'An equilibrium model of the international capital market', Journal of economic theory 8(4), 500-524.

Toseti, A., Paris, B., Paslky, P. \& Le Vallois, F. (2003), Gestion Actif Passif en Assurance vie: réglementation, outils, méthodes, Économica.

Vedani, J. \& Devineau, L. (2013), 'Solvency assessment within the ORSA framework: issues and quantitative methodologies', Bull. Fr. d'Actuar. 25, 35-71.

Weil, P. (1989), 'The equity premium puzzle and the risk-free rate puzzle', Journal of Monetary Economics 24(3), 401-421.

Wüthrich, M. V., Bühlmann, H. \& Furrer, H. (2008), Market-consistent actuarial valuation, Springer. 